\title{
GREATER PREDATION IN SHADED COFFEE FARMS: THE ROLE OF RESIDENT NEOTROPICAL BIRDS
}

\author{
Ivette Perfecto,,${ }^{1,6}$ John H. Vandermeer, ${ }^{2}$ Gustavo López Bautista, ${ }^{3}$ Guillermo Ibarra Nuñez, ${ }^{3}$ \\ Russell Greenberg, ${ }^{4}$ Peter Bichier, ${ }^{4}$ And Suzanne Langridge 5 \\ ${ }^{1}$ School of Natural Resources and Environment, University of Michigan, Ann Arbor, Michigan 48109 USA \\ ${ }^{2}$ Department of Ecology and Evolutionary Biology, University of Michigan, Ann Arbor, Michigan 48109 USA \\ ${ }^{3}$ Laboratory of Ecoethology, El Colegio de la Frontera Sur (ECOSUR), Tapachula, Chiapas, Mexico \\ ${ }^{4}$ Smithsonian Migratory Bird Center, National Zoological Park, Washington, D.C. 20008 USA \\ ${ }^{5}$ College of Environmental Sciences, University of California, Santa Cruz, California 95064 USA
}

\begin{abstract}
It is commonly thought that diverse agroecosystems are less prone to pest outbreaks because they support a high diversity of natural enemies. The idea that diversity stabilizes functional properties of communities to environmental perturbation is formalized in the ecological literature as the "insurance hypothesis." Recently this hypothesis has been examined theoretically and in microcosm experiments. However it has not been tested empirically in an agroecosystem. Here we provide a test of the insurance hypothesis by examining insect predation by birds in coffee farms with different levels of plant diversity. Lepidopteran larvae were placed in coffee plants, and larval disappearance rates were measured within and outside bird exclosures in two farms with distinct levels of shade. Significant differences were found associated with the exclosure treatment, indicating that birds can potentially prevent pest outbreaks. Furthermore, the effect was significant only for the farm with a high floristic diversity, providing partial evidence in support of the insurance hypothesis.
\end{abstract}

Key words: agricultural intensification; avian insectivory; biodiversity; biological control; Chiapas, Mexico; coffee agroecosystem; cross-trophic interactions; ecosystem function; insectivorous birds; herbivory; insurance hypothesis; natural enemies; shaded coffee farms.

\section{INTRODUCTION}

In the past few decades, cross-trophic effects have been an important feature of the development of paradigms in ecology; examples include trophic cascades (Polis et al. 2000, Schmitz et al. 2000) indirect interactions (Schmitz 1998, Dyer and Letourneau 2003), functional biodiversity (Chapin et al. 1997), and complexity-begets-stability, redressed in the language of complex systems (McCann et al. 1998, Fussman and Heber 2002, Montoya et al. 2003). Beyond their theoretical interest, cross-trophic interactions take on practical importance in agroecosystems, where, for example, successful biological control programs preceded contemporary enthusiasm for trophic cascades (Debach and Rosen 1991). Predators are generally assumed to be important agents of biological control in agroecosystems, and thus provide obvious evidence of trophic cascades (Polis et al. 2000). In this study we examine the role of insectivorous birds as regulators of herbivores and compare their impact on agroecosystems with different levels of structural and floristic diversity.

The coffee agroecosystem has recently received a great deal of attention for its role as a refuge for biodiversity (Perfecto et al. 1996, Moguel and Toledo 1999), especially for birds (Greenberg et al. 1997a, $b$ ).

Manuscript received 3 October 2003; revised 3 February 2004; accepted 26 April 2004. Corresponding Editor: J. R. Walters.

${ }^{6}$ E-mail: perfecto@umich.edu
A recent study suggests that birds have a substantial impact on the standing crop of arthropods in coffee farms (Greenberg et al. 2000). However the relationship between this observation and the role that birds play in controlling insect pests is unclear. Furthermore, as coffee farms get intensified (with the reduction or elimination of shade trees), one expects that the relationship between natural enemies and potential pests will be affected (Wilby and Thomas 2002).

It is frequently the case, especially in shaded organic coffee production, that herbivores never reach pest status and herbivory can be low (Greenberg et al. 2000). However, the potential for pest outbreaks exist, as more than 200 insect species have been reported eating coffee in Latin America (Le-Pelley 1973). Data from forest systems indicate that, although birds have little effect on prey when they are at outbreak levels (Holmes 1990), they help maintain abundances of prey populations below such levels (Holmes et al. 1979, Marquis and Whelan 1994, Strong et al. 2000, Van Bael et al. 2003). Therefore, there is reason to believe that insectivorous birds may play a role in dampening outbreaks before they occur. Relevant to these considerations is the "insurance hypothesis" (McNaughton 1977, Walker 1992, Naeem and Li 1997, Yachi and Loreau 1999, Yves et al. 2000), which holds that biodiversity stabilizes functional properties of communities to environmental perturbation. 
To test the hypotheses that more diverse agroecosystems are less prone to potential pest outbreaks, and that birds are, at least, partially responsible for lowering pest numbers, we set up an experiment in shaded coffee plantations in southern Chiapas, Mexico. Shade coffee farms support large populations of both migratory and resident birds (Greenberg et al. 1997a, $b$ ). Furthermore, experiments with bird exclosures on individual coffee plants in nearby Guatemala suggest that birds modify the insect fauna associated with coffee plants (Greenberg et al. 2000). Therefore, we simultaneously removed the effect of birds and increased the number of lepidopteran larvae, predicting that the larvae would be predated more when birds are present, and that predation rates would be higher in the more diverse shaded farm than the less diverse farm.

\section{Methods}

The two large farms chosen for this study were Finca Irlanda and Finca Hamburgo, located in the municipality of Tapachula, Chiapas, Mexico. Finca Irlanda $\left(15^{\circ} 10^{\prime} \mathrm{N}, 92^{\circ} 20^{\prime} \mathrm{W}\right)$ is an organic shaded coffee farm with high plant diversity that includes up to 200 tree species. Finca Hamburgo $\left(15^{\circ} 10^{\prime} \mathrm{N}, 92^{\circ} 19^{\prime} \mathrm{W}\right)$, on the other hand, has lower shade cover and is dominated by a few Inga species. This study was conducted taking advantage of bird exclosures that were set in November 2000 as part of another study. Vegetation characteristics were determined by setting $20 \times 20 \mathrm{~m}^{2}$ plots in such a way that the enclosed and control plants would be located approximately at the center of the plot. All non-coffee trees $\geq 10$-cm circumference were counted and identified and a total of 50 canopy-cover measurements arranged in a $10 \times 10$ grid system were made with a GRS densiometer (Geographic Resource Solutions, Arcata, California, USA) to estimate canopycover percentage for each plot.

Bird richness and density were determined by four 30 -min point counts on each plot conducted in early August 2001. During the point counts we counted the number of individuals per species every $5 \mathrm{~min}$ up to $30 \mathrm{~min}$. Total number of birds represents accumulation of the sum of 5-min counts. Bird-foraging observations were recorded over eight days on each farm for $6 \mathrm{~h}$ each day during July 2001. Observations were made at the same time on each farm, alternating observers to avoid bias. Foraging observations were conducted in the same month but during different days from the experiment so as to not cause interference with the experiment.

Eight bird exclosures were used for this study, four in the diverse site (Irlanda) and four in the site with monodominant shade (Hamburgo). Exclosures (and the corresponding controls) were separated from each other by at least $30 \mathrm{~m}$ and in some cases by as much as 300 $\mathrm{m}$. Bird exclosures were constructed of transparent monofilamentous nylon (5-cm mesh) fishing net. Each exclosure enclosed at least 10 coffee plants and was $\sim 10 \mathrm{~m}$ long, $5 \mathrm{~m}$ wide, and $3 \mathrm{~m}$ high. Control plants were selected from a parallel row of coffee approximately 2-3 $\mathrm{m}$ from the exclosure. To examine insect predation we constructed "artificial leaves" from plastic screening and plastic cocktail forks. A piece of screening (the "blade") approximately $10 \times 10 \mathrm{~cm}^{2}$ was affixed to the end of the cocktail fork (the "petiole") with water-resistant glue. The free end of the cocktail fork was attached to a branch of a coffee bush with a twist tie and Tanglefoot (The Tanglefoot Company, Grand Rapids, Michigan, USA) was applied to the petiole of the artificial leaf. Ten artificial leaves were placed on each of four coffee plants in each treatment at each site. Larvae of Estigmene acrea and Spodoptera frugiperda (graminoid specialists) were reared in the laboratory. Larvae of two sizes, approximately 3rd and 4th instars, were then transferred to the field and placed singly, one per leaf and thus 10 per plant (two plants with $S$. frugiperda and two with E. acrea) for a total of 80 larvae (40 in the enclosures and 40 in the controls) for each of the four repetitions and the two sites (a total of 640 larvae in the entire experiment). Coffee plants were supplied with individual larvae of $S$. frugiperda or E. acrea before sunrise and monitored for presence every $3 \mathrm{~h}$ until 14:00 hours, and once the following morning. One plot per farm was sampled on a different day in sequence, with all the procedures being performed at exactly the same time for each plot in each farm. The experiment was conducted between 4 and 7 July 2001. The treatment effectively mimicked a dramatic increase in the abundance of novel insect larvae. Previous sampling of the coffee plants in the same plots revealed an average density of 2.1 lepidopteran larvae per coffee plant.

If predation rate were constant, a plot of remaining larvae over time would be negative exponential. Fitting negative exponential functions to the data resulted in remarkably poor fits. Thus we presume that predation rate is not constant (with respect to number of larvae remaining) and fit a power function to the data. The exponent of the power function is taken as the rate of predation (the rate of change in the log of the number of larvae as a function of the $\log$ of time). Fits were generally good (the lowest $r^{2}$ was 0.79 , and 10 of the 16 coefficients of determinations had $\left.r^{2}>0.90\right)$. Predation rates were calculated for each treatment on each plot.

\section{RESULTS}

Bird point counts in the two sites revealed a significant difference in bird densities and species richness, concomitant with the floristic and structural diversity of the farms (Table 1).

A two-way analysis of variance shows a significant effect of both treatment $\left(F_{1,1}=11.91 ; P=0.0047\right)$ and site $\left(F_{1,1}=26.78 ; P=0.0002\right)$, with a significant interaction $\left(F_{1,1}=11.76 ; P=0.005\right)$. For a biological interpretation of the significant interaction, we graphed 
TABLE 1. Vegetation characteristics and bird densities and richness at two large coffee farms in Tapachula, Chiapas, Mexico.

\begin{tabular}{|c|c|c|c|c|c|c|}
\hline \multirow[b]{2}{*}{ Type of farm $\dagger$} & \multirow{2}{*}{$\begin{array}{l}\text { No. tree } \\
\text { species }\end{array}$} & \multirow[b]{2}{*}{ Canopy cover $(\%)$} & \multicolumn{2}{|c|}{ No. bird species } & \multicolumn{2}{|c|}{ No. bird individuals } \\
\hline & & & Total & Average $\ddagger$ & Total & Average $\ddagger$ \\
\hline Diverse shade & $7.3^{\mathrm{a}}(0.396)$ & $64.0^{\mathrm{a}}(3.978)$ & 35 & $11.66^{\mathrm{a}}(1.383)$ & 679 & $56.58^{\mathrm{a}}(9.053)$ \\
\hline Monodominant shade & $3.0^{\mathrm{b}}(0.211)$ & $30.4^{\mathrm{b}}(2.146)$ & 22 & $5.58^{\mathrm{b}}(0.679)$ & 219 & $18.25^{\mathrm{b}}(3.608)$ \\
\hline
\end{tabular}

Notes: Numbers in parenthesis represent $1 \mathrm{SE}$ of the mean. In a given column, means with different lowercase letters are significantly different at the $P<0.001$ level.

$\dagger$ Diverse shade and monodominant shade correspond to commercial polyculture and shaded monoculture, respectively, according to Moguel and Toledo's (1999) classification system.

$\ddagger$ Average number of bird species and individuals refer to the mean of 5-min counts for a total of $30 \mathrm{~min}$.

all results (Fig. 1). The significant interaction term is derived from the highly significant difference between exclosure and control on the diverse farm and the nonsignificant difference on the monodominant farm. This pattern indicates a difference in larvae-removal rates between the exclosures and control in the diverse farm but not in the farms with monodominant shade.

Foraging observations, however, do not support the idea that a higher richness of bird species is responsible for higher predation rates (Table 2). Although the bird

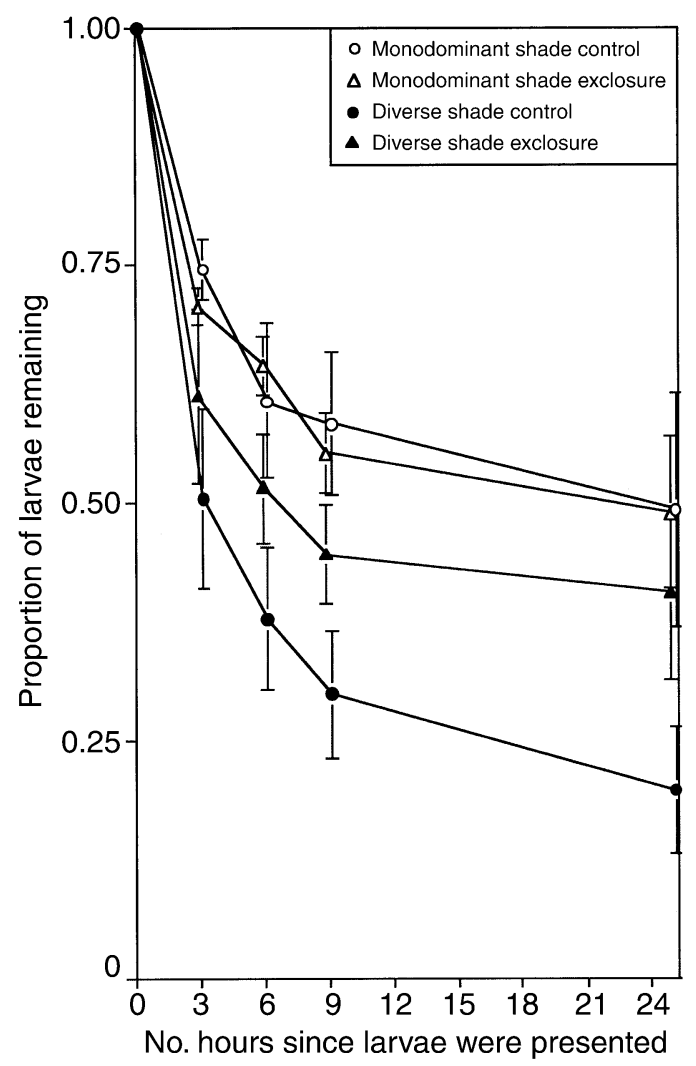

FIG. 1. Proportion of initially presented larvae remaining vs. time at two large coffee farms in Mexico, Finca Irlanda, with diverse shade ( $\sim 200$ tree species), and Finca Hamburgo, with lower monodominant shade cover (dominated by a few Inga species). Four bird exclosures were used at each site (see Methods). Data are means, and error bars represent 95\% confidence limits. Points are slightly offset on the $x$-axis to show error bars. species that are actually foraging in the coffee layer in the two farms are slightly different, the number of species foraging in the coffee layer is very similar. On the other hand, the same foraging observations suggest that a high density of a particularly effective insectivorous species might be responsible for the fast disappearance of the larvae in this study. In the diverse farm, the Rufous-capped Warbler (Basileuterus rufifrons) was observed foraging in the coffee layer 19 times, while for the same sampling effort, this species was observed foraging in the coffee layer of the monodominant farm only 7 times (Table 2).

\section{DISCUSSION}

The results support the insurance hypothesis, which states that biodiversity insures ecosystems against loss of functioning in response to environmental fluctuation or perturbations (McNaughton 1977, Yachi and Loreau 1999). In this case, the environmental change was represented by a sudden increase in the number of lepidopteran larvae. Predation on these larvae was significantly higher in the diverse farm than in the monospecific farm. The results also suggest an important potential role for birds in controlling outbreaks in diverse tropical agroforests. The current debate about the role of biodiversity in ecosystem function includes the confounding factors of species richness and density (Huston 1997, Loreau and Hector 2001). Although these two components of diversity can be separated in well-controlled microcosm experiments, they are extremely difficult to separate in more realistic natural experiments such as this one (Loreau and Hector 2001). In nature, bird species richness is often intertwined with bird density and in our experiments this is certainly the case (Table 1). Given this, we do not claim that the observed effect is due to a higher richness of bird species in the diverse agroecosystem. In the diverse farm, we recorded almost double the bird species richness compared to the monodominant farm, but also three times as many individuals. The mechanism responsible for the functioning of the insurance hypothesis could be either a higher species richness of birds and/or a higher density of particularly effective insectivorous species. A higher richness of birds could increase the chances that a novel resource would be found and exploited efficiently.

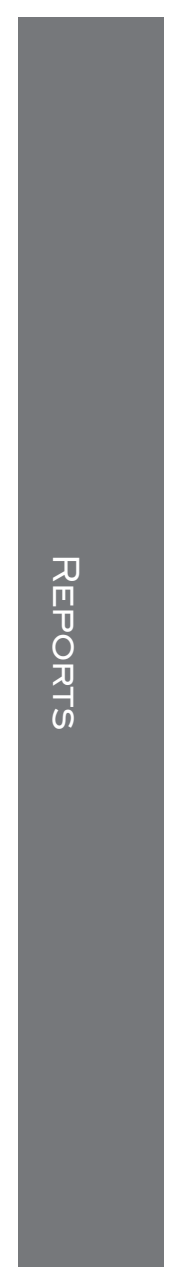


TABLE 2. Number of birds observed foraging in the coffee layer at two large coffee farms in Chiapas, Mexico.

\begin{tabular}{llcc}
\hline \hline & \multicolumn{1}{c}{ Common name } & \multicolumn{2}{c}{ No. birds observed } \\
\cline { 2 - 4 } \multicolumn{1}{c}{ Scientific name } & $\begin{array}{c}\text { Diverse } \\
\text { shade }\end{array}$ & $\begin{array}{c}\text { Monodominant } \\
\text { shade }\end{array}$ \\
\hline Thryothorus pleurostictus & Banded Wren & 4 & 0 \\
Amazilia cyanura & Blue-tailed Hummingbird & 0 & 1 \\
Myiarchus tuberculifer & Dusky-capped Flycatcher & 2 & 0 \\
Thryothorus modestus & Plain Wren & 2 & 4 \\
Synallaxis erythrothorax & Rufous-breasted Spinetail & 0 & 1 \\
Basileuterus rufifrons & Rufous-capped Warbler & 19 & 7 \\
Thryothorus maculipectus & Spot-breasted Wren & 0 & 1 \\
Piranga leucoptera & White-winged Tanager & 0 & 1 \\
Vireo flavoviridis & Yellow-green Vireo & 5 & 0 \\
Total no. species & & 5 & 6 \\
Total no. individuals & & 32 & 15 \\
\hline
\end{tabular}

In the various debates surrounding the question of biodiversity and ecosystem function, the notion of the "sampling effect" is relevant (Huston 1997, Loreau and Hector 2001). The sampling effect would suggest that in the diverse agroecosystem one or perhaps only a few species are responsible for the observed increase in ecosystem function. In other words, the sampling effect indicates that diversity per se is not what is responsible for the increased ecosystem function but rather that the higher diversity increases the probabilities that a highly efficient species is present and that it is this species (or perhaps a reduced set of efficient species) that is responsible for the increased ecosystem function. In the context of this study, it is possible that one species, Basileuterus rufifrons was responsible for most of the predation in the diverse farm, and it was only because this farm had more individuals of this species than did the monodominant farm that predation rates were higher in the more diverse farm. This mechanism provides another explanation of the diversity effect and the insurance hypothesis.

It is important to point out two significant caveats of the experimental design. First, although there were four replicates per farm, the farms (or sites) were not replicated. This means that the observed differences in predation between the farms might be due to the difference in floristic and structural diversity between the farms (Table 1), thus conforming to our hypothesis, but they could also be due to other site differences. For example, it is possible that abiotic conditions that affect bird foraging behavior were different between the two sites. Given this lack of replication at the site level we remain cautious with our general conclusion. Second, the physical exclosures could have diverted birds that would normally forage on the plants within the exclosures to the control plants, accentuating the differences between the exclosures and the control. However, given the highly significant statistical effect of the exclosures, we feel confident that even if this was happening, the conclusions that birds prey more on the larvae and can potentially prevent outbreaks in diverse farms still holds.

Finally, it is important to note that after 24 hours more than $40 \%$ of the larvae had been removed from all treatments (including the exclosures), suggesting that predators other than birds are also taking the larvae. Other observations in these plantations indicate that there is a high density of spiders. Jumping spiders could potentially gain access to the artificial leaves and remove small larvae. Other flying predators that have been observed in this system and that could potentially remove small larvae are rubber flies and predatory wasps. However, all of these other predators can easily move in and out of the exclosures and therefore the significant difference between exclosures and controls within the diverse farm cannot be attributed to them and are more likely the result of bird predation.

Structurally and floristically diverse agroecosystems harbor a higher density and diversity of birds (Greenberg et al. 1997a, $b$ ). This abundant and diverse bird community may have little or no noticeable effect on herbivores under normal circumstances. But when, in an imagined future, something about the ecosystem changes (as it inevitably does), one or more of the components of that community can act to buffer the system from an extreme negative response (McNaughton 1977). This should be carefully considered when promoting the intensification and simplification of diverse agroecosystems such as those that are still important in the tropics and that provide sustenance and income for millions of poor farmers in the developing world.

\section{ACKNOWLEDGMENTS}

This work was supported by a grant from NSF (DBE9981526). We also appreciate help from Armando Virgen Sánchez and Dr. Julio Rojas in rearing caterpillars. We wish to thank Mr. Walter Peters and Mr. Tomas Edelman for allowing us to conduct this experiment on their farms. Braulio Esteban Chilel helped with the maintenance of the exclosures. Finally, the manuscript was greatly enhanced by discussions with Stacy Philpott, Tom Dietsch, and Alvaro García Ballinas. 


\section{Literature Cited}

Chapin, F. S., III, B. H. Walker, R. J. Hobbs, D. U. Hooper, J. H. Lauton, O. E. Sala, and D. Tilman. 1997. Biotic control over the functioning of ecosystems. Science 277: $500-504$

Debach, P., and R. Rosen. 1991. Biological control by natural enemies. Second edition. Cambridge University Press, Cambridge, UK.

Dyer, L. A., and D. Letourneau. 2003. Top-down and bottomup diversity cascades in detrital vs. living food webs. Ecology Letters 6:60-68.

Fussman, G. F., and G. Heber. 2002. Food web complexity and chaotic population dynamics. Ecology Letters 5:394401.

Greenberg, R., P. Bichier, A. Cruz-Angon, C. MacVean, R. Perez, and E. Cano. 2000. The impact of avian insectivory on arthropods and leaf damage in some Guatemalan coffee plantations. Ecology 81:1750-1755.

Greenberg, R., P. Bichier, A. Cruz Angon, and R. Reitsma. 1997a. Bird populations in shade and sun coffee plantations in Central Guatemala. Conservation Biology 11:448459.

Greenberg, R., P. Bichier, and J. Sterling. 1997b. Bird populations in rustic and planted shade coffee plantations of Eastern Chiapas, México. Biotropica 29:501-514.

Holmes, R. T. 1990. Ecological and evolutionary impacts of bird predation on forest insects: an overview. Studies in Avian Biology 13:6-13.

Holmes, R. T., J. C. Schultz, and P. Nothnagle. 1979. Bird predation on forest insects: an exclosure experiment. Science 206:462-463.

Huston, M. A. 1997. Hidden treatments in ecological experiments: re-evaluating the ecosystem function of biodiversity. Oecologia 110:449-460.

Le-Pelley, R. H. 1973. Coffee insects. Annual Review of Entomology 18:121-142.

Loreau, M., and A. Hector. 2001. Partitioning selection and complementarity in biodiversity experiments. Nature $\mathbf{4 1 2}$ : $72-76$.

Marquis, R. J., and J. C. Whelan. 1994. Insectivorous birds increase growth of white oak through consumption of leafchewing insects. Ecology 75:2007-2014.
McCann, K., A. Hastings, and G. R. Huxel. 1998. Weak trophic interactions and the balance of nature. Nature 395: 794-798.

McNaughton, S. J. 1977. Diversity and stability of ecological communities: a comment on the role of empiricism in ecology. American Naturalist 111:515-525.

Moguel, P., and V. M. Toledo. 1999. Biodiversity conservation in traditional coffee systems in Mexico: a review. Conservation Biology 12:1-11.

Montoya, J. M., M. A. Rodriguez, and B. A. Hawkins. 2003. Food web complexity and higher-level ecosystem services. Ecology Letters 6:587-593.

Naeem, S., and S. Li. 1997. Biodiversity enhances ecosystem reliability. Nature 390:507-509.

Perfecto, I., R. Rice, R. Greenberg, and M. Van der Voolt. 1996. Shade coffee as refuge of biodiversity. BioScience 46:598-608.

Polis, G. A., A. L. W. Sears, G. R. Huxel, D. R. Strong, and J. Maron. 2000. When is a trophic cascade a trophic cascade? Trends in Ecology and Evolution 15:473-475.

Schmitz, O. J. 1998. Direct and indirect effects of predation and predation risk in old-field interaction webs. American Naturalist 151:327-342.

Schmitz, O. J., P. A. Hambäck, and A. P. Beckerman. 2000. Trophic cascades in terrestrial systems: a review of the effects of carnivore removal on plants. American Naturalist 155: $141-153$.

Strong, A. M., T. W. Sherry, and R. T. Holme. 2000. Bird predation on herbivorous insects: indirect effects on sugar maple saplings. Oecologia 125:370-379.

Van Bael, S. A., J. D. Brawn, and S. K. Robinson. 2003. Proceedings of the National Academy of Sciences (USA) 100: $8304-8307$.

Walker, B. H. 1992. Biodiversity and ecological redundancy. Conservation Biology 6:18-23.

Wilby, A., and M. B. Thomas. 2002. Natural enemy diversity and pest control: patterns of pest emergence with agricultural intensification. Ecology Letters 5:353-360.

Yachi, S., and M. Loreau. 1999. Biodiversity and ecosystem productivity in a fluctuating environment: the insurance hypothesis. PNAS 96:1463-1468.

Yves, A. R., J. L. Klung, and K. Gross. 2000. Stability and species richness in complex communities. Ecology Letters 3:399-411. 